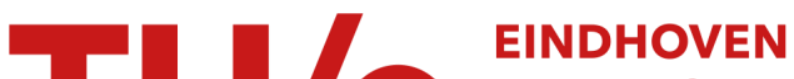 \\ UNIVERSITY OF \\ TECHNOLOGY
}

\section{Tracking of particles using TFM in gas-solid fluidized beds}

Citation for published version (APA):

Banaei, M., Jegers, J., van Sint Annaland, M., Kuipers, J. A. M., \& Deen, N. G. (2018). Tracking of particles using TFM in gas-solid fluidized beds. Advanced Powder Technology, 29(10), 2538-2547.

https://doi.org/10.1016/j.apt.2018.07.007

\section{Document license:}

TAVERNE

DOI:

10.1016/j.apt.2018.07.007

Document status and date:

Published: 01/10/2018

\section{Document Version:}

Publisher's PDF, also known as Version of Record (includes final page, issue and volume numbers)

\section{Please check the document version of this publication:}

- A submitted manuscript is the version of the article upon submission and before peer-review. There can be important differences between the submitted version and the official published version of record. People interested in the research are advised to contact the author for the final version of the publication, or visit the $\mathrm{DOI}$ to the publisher's website.

- The final author version and the galley proof are versions of the publication after peer review.

- The final published version features the final layout of the paper including the volume, issue and page numbers.

Link to publication

\section{General rights}

Copyright and moral rights for the publications made accessible in the public portal are retained by the authors and/or other copyright owners and it is a condition of accessing publications that users recognise and abide by the legal requirements associated with these rights.

- Users may download and print one copy of any publication from the public portal for the purpose of private study or research.

- You may not further distribute the material or use it for any profit-making activity or commercial gain

- You may freely distribute the URL identifying the publication in the public portal.

If the publication is distributed under the terms of Article $25 \mathrm{fa}$ of the Dutch Copyright Act, indicated by the "Taverne" license above, please follow below link for the End User Agreement:

www.tue.nl/taverne

Take down policy

If you believe that this document breaches copyright please contact us at:

openaccess@tue.nl

providing details and we will investigate your claim. 
Original Research Paper

\title{
Tracking of particles using TFM in gas-solid fluidized beds
}

\author{
M. Banaei ${ }^{\text {a,b,*, J. Jegers }}{ }^{\text {a }}$, M. van Sint Annaland ${ }^{\text {a,b }}$, J.A.M. Kuipers ${ }^{\text {a,b }}$, N.G. Deen ${ }^{\text {b,c }}$ \\ ${ }^{a}$ Multiphase Reactors Group, Department of Chemical Engineering E Chemistry Eindhoven University of Technology, P.O. Box 513, 5600 MB Eindhoven, The Netherlands \\ ${ }^{\mathrm{b}}$ Dutch Polymer Institute (DPI), P.O. Box 902, 5600 AX Eindhoven, The Netherlands \\ ${ }^{\mathrm{c}}$ Multiphase and Reactive Flows Group, Department of Mechanical Engineering, Eindhoven University of Technology, P.O. Box 513, 5600 MB Eindhoven, The Netherlands
}

\section{A R T I C L E I N F O}

\section{Article history:}

Received 3 October 2017

Received in revised form 30 May 2018

Accepted 12 July 2018

Available online 24 July 2018

\section{Keywords:}

Gas-solid fluidized beds

Two fluid model

Solids mixing

Restitution coefficient

Superficial gas velocity

\begin{abstract}
A B S T R A C T
In this work, a new method is presented to track discrete tracer particles in a two fluid model (TFM). This method is particularly useful for studying features of discrete particles, such as solids mixing. Following the implementation and verification of this method, its accuracy was studied. The results showed that the new method fulfills the continuity equation and it can represent individual solids motion very well. This method may suffer from false diffusion, which can be diminished by selecting a sufficiently small grid size. In addition, it has several advantages over other techniques, like simplicity, ease of implementation, straightforward processing and enabling the calculation of a mixing index based on the initial neighbor distance concept. Moreover, this method can open a new way to combine the TFM with Lagrangian approaches. After analyzing the strengths and drawbacks of our method and finding the proper simulation settings, the effects of superficial gas velocity and restitution coefficient on solids mixing were investigated. The results showed that the solids mixing is enhanced by increasing the gas velocity and/or decreasing the restitution coefficient. The observed trends can be attributed to altered bubble formation and dynamics. These results also confirm our earlier findings on the solids temperature distribution in fluidized beds for polyolefins production (Banaei et al., 2017).
\end{abstract}

(c) 2018 The Society of Powder Technology Japan. Published by Elsevier B.V. and The Society of Powder Technology Japan. All rights reserved.

\section{Introduction}

Gas-solid fluidized beds have been used in various physical and chemical processes for several decades. Due to their importance and their wide range of applications, numerous experimental and simulation techniques have been introduced to understand the behavior of these contactors. Simulation techniques have become increasingly interesting to researchers because of the enormous improvements in the performance of computer processors during the last several years. As a consequence, several mathematical models have been presented and examined for the prediction of fluidized bed reactors. These models can even give some detailed information about the fluidized bed features that are not easily accessible through experiments. The two fluid model (TFM) based on the kinetic theory of granular flow (KTGF) is one of these models that has been used for the prediction of the behavior of fluidized beds.

\footnotetext{
* Corresponding author at: Multiphase Reactors Group, Department of Chemical Engineering \& Chemistry Eindhoven University of Technology, P.O. Box 513, 5600 MB Eindhoven, The Netherlands.

E-mail address: mohammad.banaei@outlook.com (M. Banaei).
}

The TFM is an Eulerian-Eulerian model and considers the gas and the solids phase(s) as continuum phases. In other words, the continuity equation and the volume-averaged Navier-Stokes equations are used in this model to describe the gas and solids motion. This model has been validated and used by many researchers in the field of fluidization and it has shown its strength in different aspects [2-5]. However, this model has some drawbacks as well. For example, it is not feasible to track individual particles with this model. As a result, it is not straightforward to calculate the solids mixing patterns with the TFM. In one of our earlier works, a new method for overcoming this difficulty was introduced and the deficiencies of other approaches were investigated [6]. In the earlier proposed approach, the solids phase was divided into several colored groups and the motion of each group was obtained by solving the scalar convection equations. Even though the solids mixing rate and the solids mixing pattern can be obtained by this technique, it is not possible to track individual particles. In this work, another methodology for the calculation of the solids mixing is introduced. The main advantage of this method is that individual particles can be tracked, which opens a new window for combining the TFM with Lagrangian approaches. In addition, the new method makes quantification of the solids mixing much more straightforward. For example, there is no need to perform two different sets 


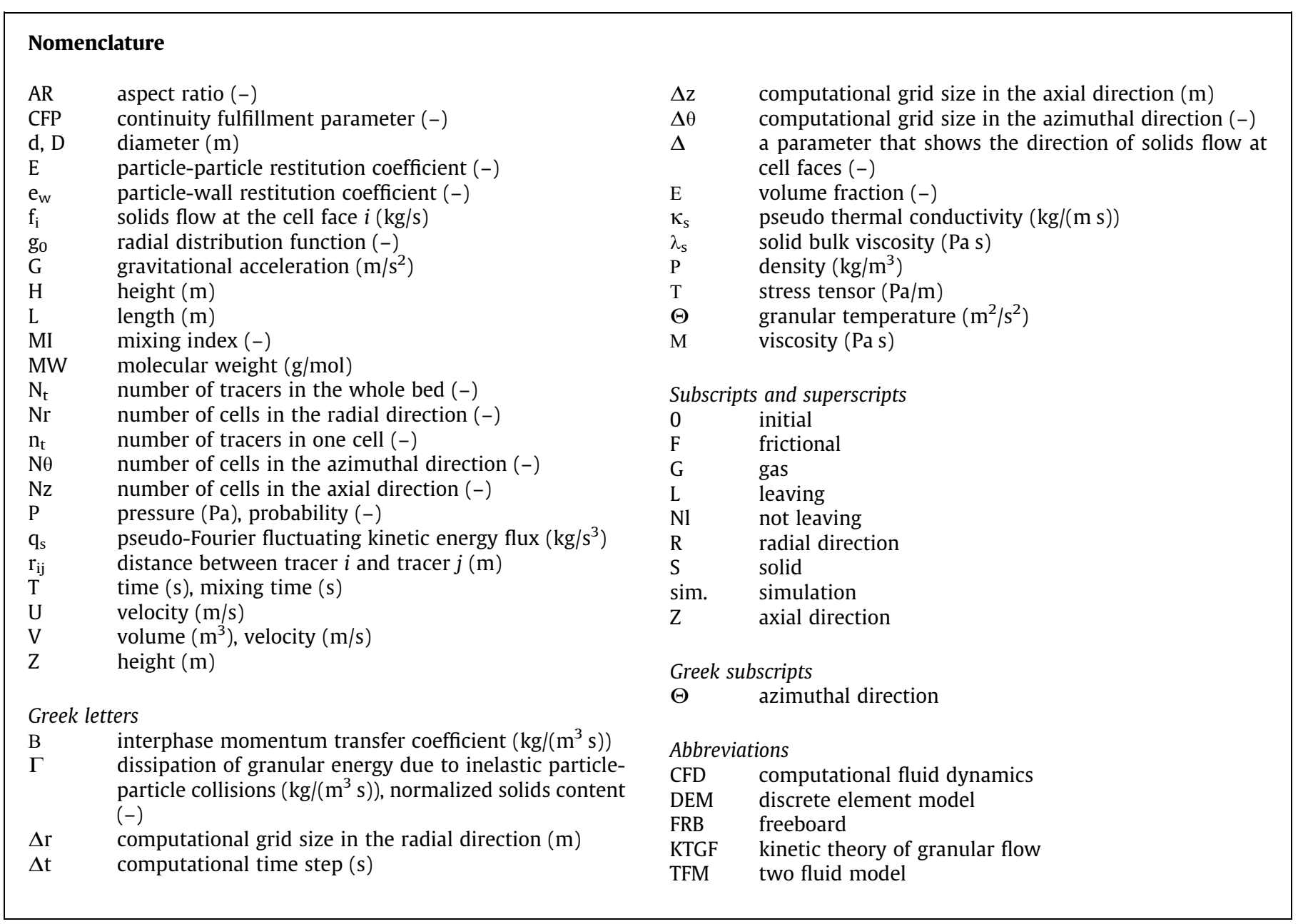

of simulations or solve mixing equations twice with different initial settings to obtain the solids mixing rate in the horizontal and vertical directions.

This method has a high level of accuracy and it can be implemented very easily because of its simple concept, as will be explained in detail later. In this sections, the new method will be demonstrated to study the solids mixing in poly-olefin fluidized beds. In earlier work, it is showed that the solids mixing rate has a profound effect on the probability of hot-spot formation [1]. For this reason, the results of this work complement our earlier research. Additionally, the new method can also be used to investigate the solids mixing in other applications, especially when other techniques like the discrete element model (DEM) would require too much computational time.

This paper is organized as follows. After the description, implementation and verification of the method, the fulfillment of the solids phase continuity equation by this technique is checked. Subsequently, the sensitivity of the model results with respect to the time step and computational cell size is examined. Moreover, also deficiencies of this technique are investigated. Finally, the effect of the superficial gas velocity and restitution coefficient on the mixing rate of particles is explored and the results are analyzed and discussed thoroughly.

\section{Governing equations}

The mathematical representation of the TFM governing equations are given in Table 1 where Eqs. (1) and (2) present the mass conservation or continuity equations for the gas and solids phases respectively. Eqs. (3) and (4) are the volume-averaged NavierStokes equations for both phases. Eq. (5) is the granular temperature equation that describes the kinetic energy associated with the solids phase fluctuating motion.

The governing equations are closed with closures that were previously presented by Nieuwland et al. [7] and are given in Table 2.

Details about the implementation and verification of these equations was presented by Verma et al. [12]. The finite difference technique was used to solve the TFM equations. The interested reader is referred to the aforementioned work for further details about the applied numerical algorithms and verification steps.

\section{Tracking of particles}

The method for tracking individual particles consists of several steps and it starts with the initialization of tracers in the bed based on the solids content in every computational cell. After solving the

Table 1

TFM governing equations in vector form based on the KTGF.

$\frac{\partial}{\partial t}\left(\varepsilon_{g} \rho_{g}\right)+\cdot\left(\varepsilon_{g} \rho_{g} \vec{u}_{g}\right)=0$
$\frac{\partial}{\partial t}\left(\varepsilon_{s} \rho_{s}\right)+\cdot\left(\varepsilon_{s} \rho_{s} \vec{u}_{s}\right)=0$
$\frac{\partial}{\partial t}\left(\varepsilon_{g} \rho_{g} \vec{u}_{g}\right)+\cdot\left(\varepsilon_{g} \rho_{g} \vec{u}_{g} \vec{u}_{g}\right)=-\varepsilon_{g} P_{g}-\cdot\left(\varepsilon_{g} \vec{\tau}_{g}\right)-\beta\left(\vec{u}_{g}-\vec{u}_{s}\right)+\varepsilon_{g} \rho_{g} \vec{g}$
$\frac{\partial}{\partial t}\left(\varepsilon_{s} \rho_{s} \vec{u}_{s}\right)+\cdot\left(\varepsilon_{s} \rho_{s} \vec{u}_{s} \vec{u}_{s}\right)=-\varepsilon_{s} P_{g}-P_{s}-\cdot\left(\varepsilon_{s} \vec{\tau}_{s}\right)+\beta\left(\vec{u}_{g}-\vec{u}_{s}\right)+\varepsilon_{s} \rho_{s} \vec{g}$
$\frac{3}{2}\left[\frac{\partial}{\partial t}\left(\varepsilon_{s} \rho_{s} \theta\right)+\cdot\left(\varepsilon_{s} \rho_{s} \theta \vec{u}_{s}\right)\right]=-\left(P_{s} \overrightarrow{\vec{I}}+\varepsilon_{s} \overrightarrow{\vec{\tau}}_{s}\right): \vec{u}_{s}-\cdot\left(\varepsilon_{s} q_{s}\right)-3 \beta \theta-\gamma$


Table 2

Two-fluid model, closure equations [7].

Particulate-phase pressure:

$P_{s}=\left(1+2\left(1+e_{n}\right) \varepsilon_{s} g_{0}\right) \varepsilon_{s} \rho_{s} \theta$

Newtonian stress-tensor:

$\overrightarrow{\vec{\tau}}_{s}=-\left[\left(\lambda_{s}-\frac{2}{3} \mu_{s}\right)\left(. \vec{u}_{s}\right) \overrightarrow{\vec{I}}+\mu_{s}\left(\left(\vec{u}_{s}\right)+\left(\vec{u}_{s}\right)^{T}\right)\right]$

Bulk viscosity:

$\lambda_{s}=\frac{4}{3} \varepsilon_{s} \rho_{s} d_{p} g_{0}\left(1+e_{n}\right) \sqrt{\frac{\theta}{\pi}}$

Shear viscosity:

$\mu_{s}=1.01600 \frac{5}{96} \pi \rho_{s} d_{p} \sqrt{\frac{\theta}{\pi}} \frac{\left(1+\frac{8\left(1+e_{n}\right)}{2} \varepsilon_{s} g_{0}\right)\left(1+\frac{8}{5} \varepsilon_{s} g_{0}\right)}{\varepsilon_{s} g_{0}}+\frac{4}{5} \varepsilon_{s} \rho_{s} d_{p} g_{0}\left(1+e_{n}\right) \sqrt{\frac{\theta}{\pi}}+\mu_{s}^{f}$

Pseudo-Fourier fluctuating kinetic energy flux:

$q_{s}=-\kappa_{s} \theta$

Pseudo-thermal conductivity

$\kappa_{s}=1.02513 \frac{75}{384} \pi \rho_{s} d_{p} \sqrt{\frac{\theta}{\pi}} \frac{\left(1+\frac{12\left(1+e_{n}\right)}{2} \varepsilon_{s} g_{0}\right)\left(1+\frac{12}{5} \varepsilon_{s} g_{0}\right)}{\varepsilon_{s} g_{0}}+2 \varepsilon_{s} \rho_{s} d_{p} g_{0}\left(1+e_{n}\right) \sqrt{\frac{\theta}{\pi}}$

Dissipation of granular energy due to inelastic particle-particle collisions:

$\gamma=3\left(1-e_{n}^{2}\right) \varepsilon_{s}^{2} \rho_{s} g_{0} \theta\left[\frac{4}{d_{p}} \sqrt{\frac{\theta}{\pi}}-\left(\cdot \vec{u}_{s}\right)\right]$

Radial distribution function [8]:

$g_{0}=1+4 \varepsilon_{s} \frac{1+2.5 \varepsilon_{s}+4.5904 \varepsilon_{s}^{2}+4.515439 \varepsilon_{s}^{2}}{\left(1-\left(\frac{\varepsilon_{s}}{\varepsilon_{s} \max }\right)^{3}\right)^{0.67802}}$

$\varepsilon_{s, \max }=0.64356$

Frictional stress model [9]:

$\mu_{s}^{f}=\frac{p_{c} \sqrt{2} \sin \phi}{2 \varepsilon_{s} \sqrt{\left(\overrightarrow{\left.\overrightarrow{D_{i j}} \cdot \overrightarrow{D_{i j}}+\theta / d_{p}^{2}\right)}\right.}}, \overrightarrow{D_{i j}}=\left(\frac{1}{2}\left(\left(\vec{u}_{s}\right)+\left(\vec{u}_{s}\right)^{T}\right)-\frac{1}{3} \cdot \vec{u}_{s} \overrightarrow{\vec{I}}\right)$

$p_{c}=\left\{\begin{array}{cl}F \frac{\left(\varepsilon_{s}-\varepsilon_{s, \min }\right)}{\left(\varepsilon_{s, \max }-\varepsilon_{s}\right)^{5}} & \varepsilon_{s}>\varepsilon_{s, \min } \\ 0 & \varepsilon_{s}<\varepsilon_{s, \min }\end{array}[10]\right.$

$F=0.05\left(\mathrm{~N} / \mathrm{m}^{2}\right), r=2, s=3, \varepsilon_{s, \min }=0.5, \phi=28^{\circ}[11]$

TFM equations, for each grid cell we can calculate the solids flow rate through each of the eight cell faces. Based on the magnitude and the sign of all flows, the probability of a tracer leaving a cell and the direction in which it leaves can be calculated. Fig. 1 present the pseudo-algorithm for this method. This procedure should be repeated until the end of the simulation.

There are some assumptions that were used in this method. We will now explain these assumptions on the basis of a simple 2D example. Imagine that a certain computational cell has four neighbors and it contains $n_{t, \text { cell }}$ tracers. The neighbors of this cell are denoted by their direction $i \in$ [North, South, East and West] (see Fig. 2a). The TFM provides us with the solids flow rates $f_{i}$ through each of the cell faces. A delta function is used to indicate the direc-

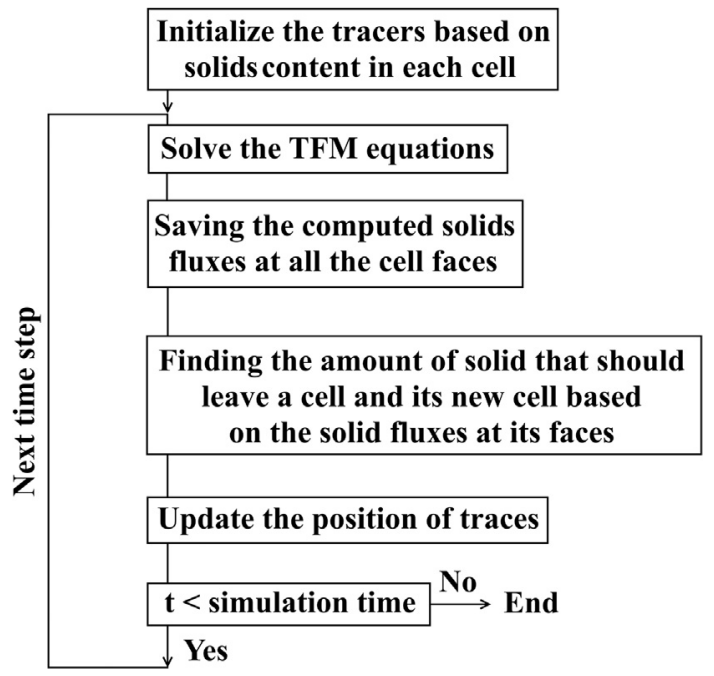

Fig. 1. Pseudo-algorithm of tracking particles in the TFM. (a)

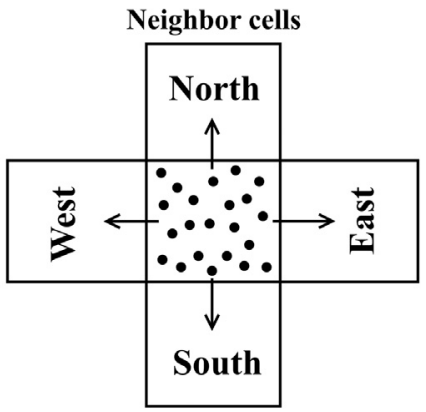

(b) Leaving or staying probabilty distribution

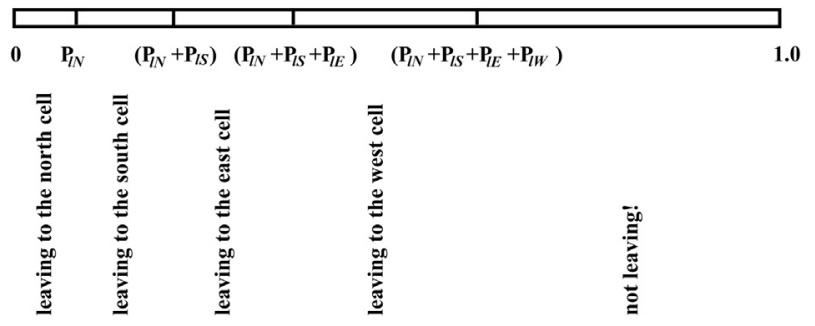

Fig. 2. Neighbor cells and leaving or staying probability distribution.

tion of the flow (e.g. $\delta_{\mathrm{i}}=1$ if the flow is out of the cell and $\delta_{\mathrm{i}}=0$ if the flow is into the cell):

$\delta_{i}=\frac{\left(1+\operatorname{sign}\left(f_{i}\right)\right)}{2}$

The flows leaving the cell are used to calculate the probability that the tracer actually leaves the grid cell, which for direction $i$ is given by:

$P_{l i}=\frac{f_{i} \delta_{i}}{f_{n l}+\sum_{\text {all neighbours }} f_{i} \delta_{i}}=\frac{f_{i} \delta_{i}}{\varepsilon_{s} \rho_{s} V_{\text {cell }} / \Delta t}$

Where $f_{n l}$ represents the sum of the "non-leaving flows", which is given by:

$f_{n l}=\varepsilon_{s} \rho_{s} V_{\text {cell }} / \Delta t-\sum_{\text {all neighbours }} f_{i} \delta_{i}$

The associated probability is given by:

$P_{n l}=\frac{f_{n l}}{f_{n l}+\sum_{\text {all neighbours }}\left(f_{i} \delta_{i}\right)}=1-\sum_{\text {all neighbours }} P_{i l}$

Based on these equations, $P_{l i}$ will be zero if the leaving solids flow at a cell face is negative, or - in other words - the solids only enter the investigated cell through that cell face. Note that by definition, the summation of the probabilities of all leaving flows $P_{l i}$ and the probability of not leaving is equal to one. The different probabilities can be arranged as shown in Fig. 2b. After finding the probability distribution for the cell, $n_{t, \text { cell }}$ random numbers between zero and one are generated. Based on the values of these random numbers, each tracer will be moved to its new cell or it stays in the same cell. The relative position of the tracers in their new cell is determined randomly.

The procedure for moving tracers should be done for every individual tracer and at every time step because the solids flux and the solids volume fraction change over time and space. Suppose that the leaving probabilities for the cell which is shown in Fig. 2a are calculated by Eqs. (7)-(9) at $t=t_{0}$ and imagine that the final values are as follows: leaving probability from the North cell: $10 \%$, from 
the South cell: $20 \%$, from the East cell: $15 \%$ and from the West cell: $0 \%$. In other words, $P_{I N}=10 \%, P_{I S}=20 \%, P_{l E}=15 \%, P_{l W}=0 \%$ and $P_{n l}=55 \%$. In such a case, we need to generate one random number like $r_{i}$ between 0 and 1 for every existing individual tracer in that cell. If $0<r_{i} \leq P_{I N}=0.1$, that specific tracer will be moved to the north cell. If $P_{I N}=0.1<r_{i} \leq P_{I N}+P_{I S}=0.30$, that tracer will be moved to the south cell. If $P_{I N}+P_{I S}=0.3<r_{i} \leq P_{I N}+P_{I S}+P_{I E}=0.45$, then the tracer will be moved to the east cell. If $r_{i}$ is larger than or equal to 0.45 , then it will stay in the same cell until the next time-step. In this specific example, the tracers will not move to the west cell within this investigated time step because $P_{I W}$ is zero. This procedure will be done for all the tracers in all the computational cells. Then, the TFM equations will be solved and after that it is necessary to calculate the solids fluxes and leaving probabilities for all the cells again and the whole procedure should be repeated. Fig. 3 shows a flowchart for this procedure.

After implementation of the new method and its verification, several simulations were performed and some snapshots from the simulations are presented in Fig. 4.

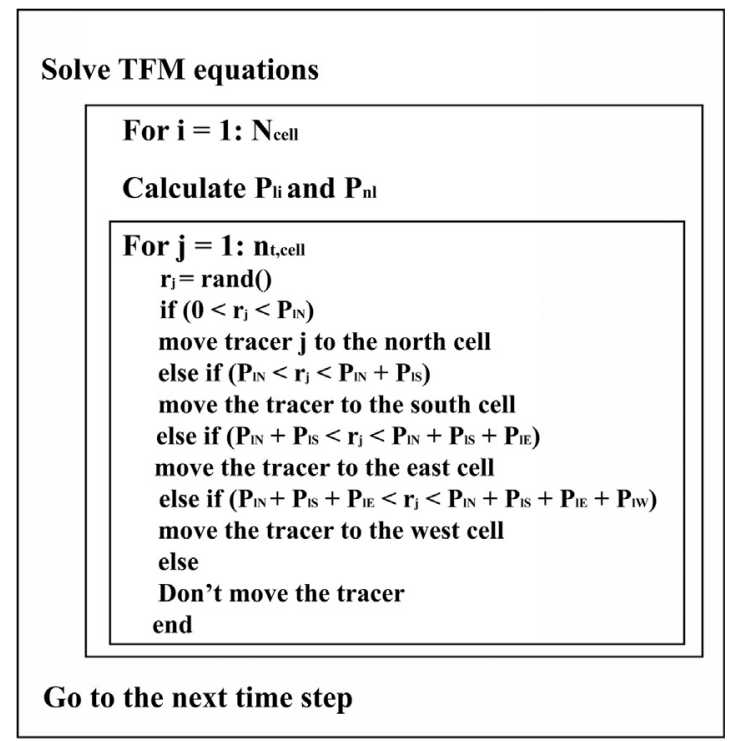

Fig. 3. Flowchart of moving tracers.
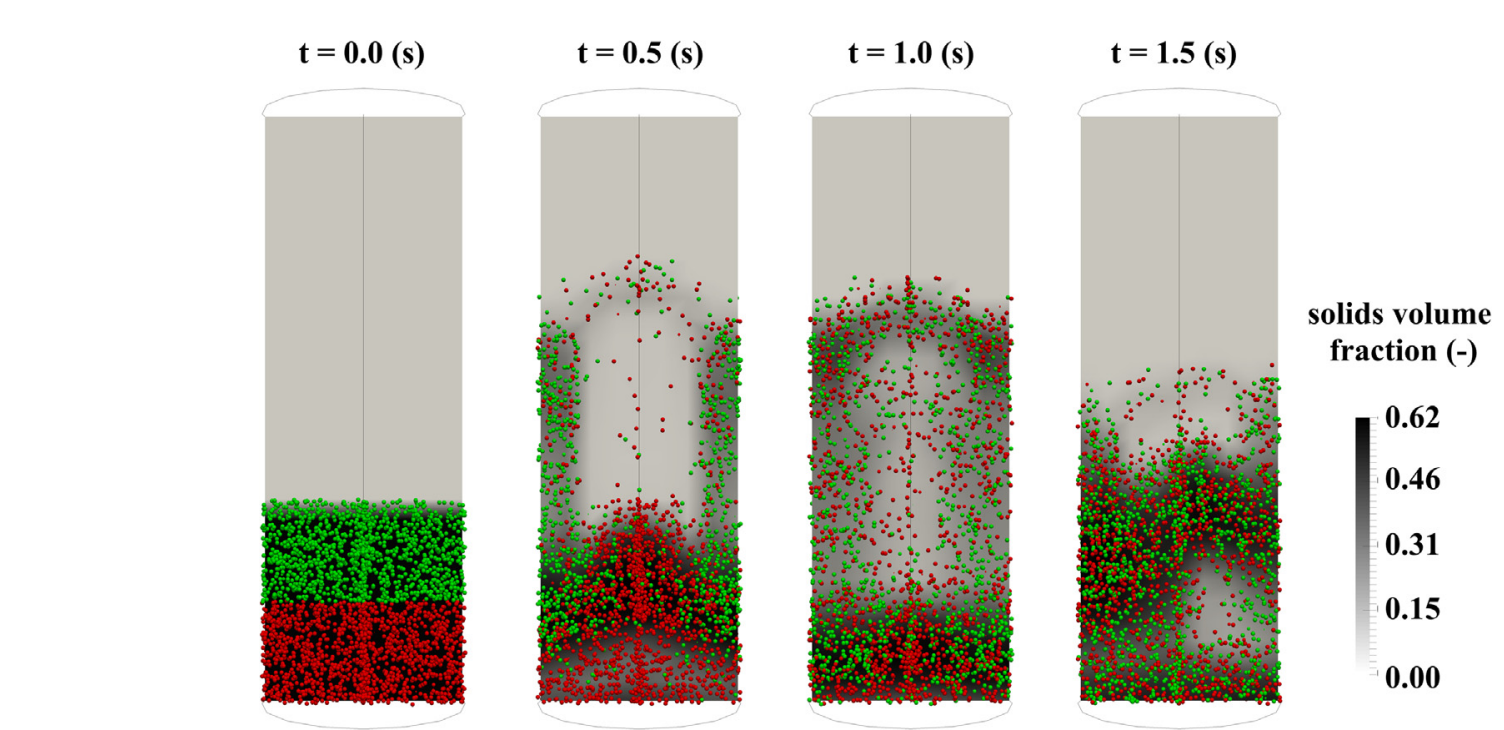

\section{Accuracy of the method}

Following the implementation of all the necessary routines for tracking the individual particles (tracers), the accuracy of this technique was assessed. The results of this analysis in addition to the time step and grid sensitivity analysis are presented in this section. Additionally, the sensitivity of the simulation results to the number of tracers and the number of time-averaging periods are also discussed in this part of the work.

\subsection{Sensitivity to the number of tracers}

As a first step in the accuracy analysis, the sensitivity of the solids mixing to the number of tracers was investigated. For this purpose, several simulations with different numbers of tracers were performed. The simulation conditions and their naming are presented in Tables 3 and 4 respectively. After performing the simulations, the time evolution of the initial neighbor distance mixing index [13] was calculated and the final results are presented in Fig. 5. The mixing index is defined as:

$M I=\frac{\sum_{i=1}^{N_{t}} r_{i j}}{\sum_{i=1}^{N_{t}} r_{i k}}$

where $r_{i j}$ is the distance between tracer $i$ and its initially nearest neighbor $j, r_{i k}$ is the distance between tracer $i$ and a randomly selected tracer $k$ and $N_{t}$ is the number of tracers in the entire bed. This mixing index has a couple of advantages over other mixing indices based on the average height or the Lacey index. The results of this mixing index are reproducible, and independent of grid and color. Also, this index considers the solids mixing in all three directions [13]. For this reason, this index is used in this work.

Based on the results shown in Fig. 5, the mixing index evolution does not depend on the number of tracers, even if the number of tracers is only $5 \%$ of the actual number of particles in the system. It should be added that other mixing indices may be more sensitive to the number of tracers. For example, the mixing index that has been defined by Banaei et al. [6] has a much higher sensitivity to the number of tracers compared to the initial neighbor distance mixing index. If a mixing index is defined based on the coloring/ labeling of the particles and the concentration of colored particles, the number of tracers should be sufficiently high in each cell to

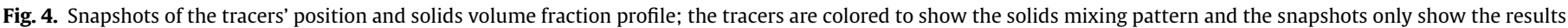
at a slice in the center of the bed. 
Table 3

Simulation conditions for sensitivity analysis to the number of tracers.

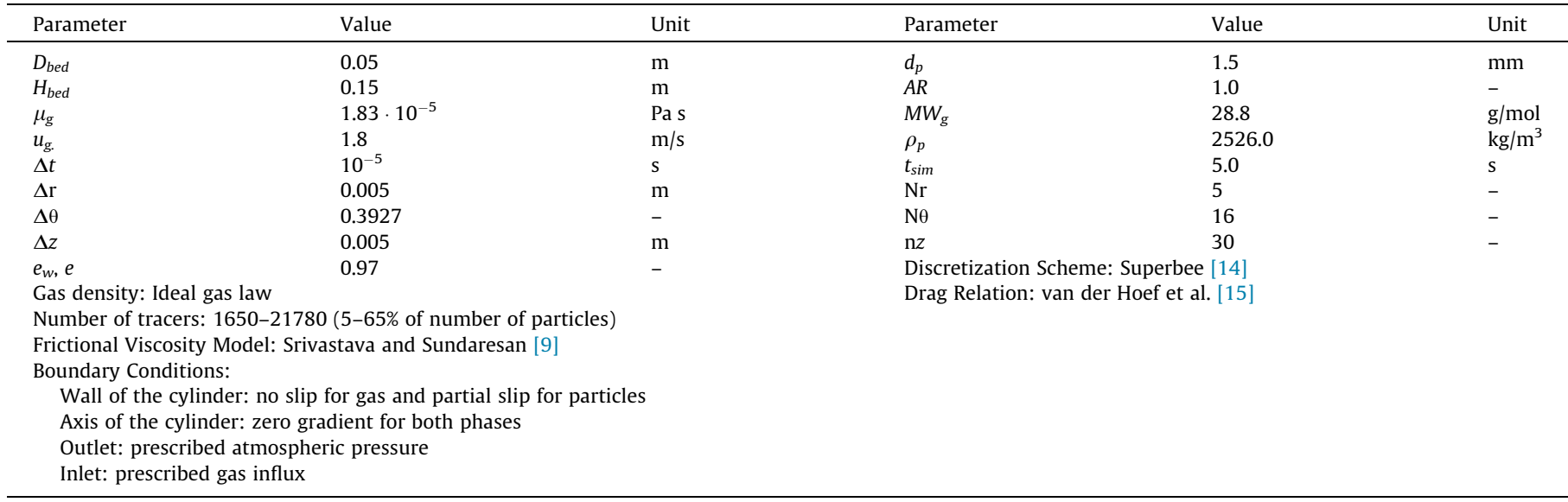

Table 4

Naming of simulations for sensitivity analysis to the number of tracers.

\begin{tabular}{lll}
\hline Name of the simulation & Number of tracers & $N_{t} / N_{p}$ percentage \\
\hline Case A & 21,780 & 65.3 \\
Case B & 16,500 & 49.5 \\
Case C & 10,890 & 32.7 \\
Case D & 5280 & 15.8 \\
Case E & 3300 & 9.9 \\
Case F & 1650 & 5.0 \\
\hline
\end{tabular}

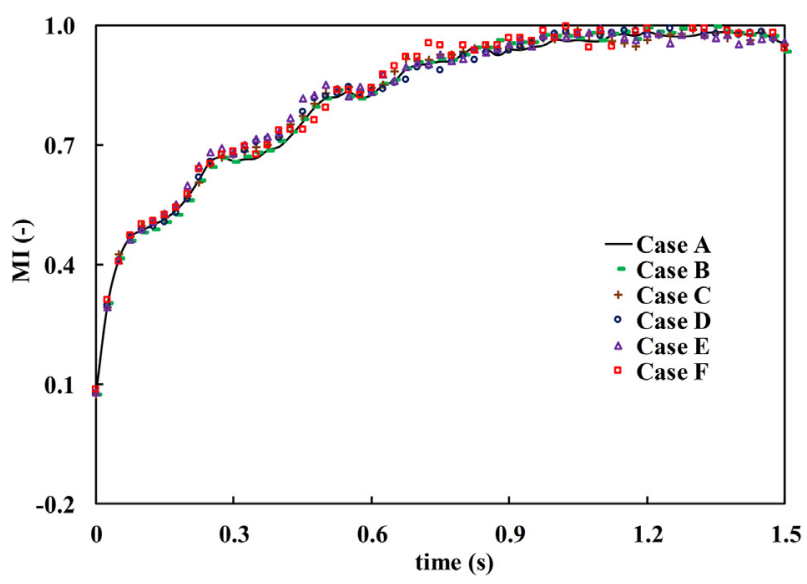

Fig. 5. Sensitivity of the mixing index evolution to the number of tracers.

obtain sufficiently accurate statistics. However, such an issue was not observed for the initial neighbor distance mixing index in the performed simulations.

\subsection{Continuity fulfilment and its sensitivity to the number of tracers}

The second accuracy analysis that was carried out is based on the fulfillment of the solids phase continuity equation. Banaei et al. [6] introduced a parameter for this purpose that is defined by Eqs. (11)-(13). This parameter indicates how well the number of tracers in each cell corresponds to the solids content of the cell.

$\left(n_{t, n}\right)_{i, j, k}=\frac{\left(n_{t}\right)_{i, j, k}}{\sum_{\text {all cells }}\left(n_{t}\right)_{i, j, k}}$

$(\gamma)_{n, i, j, k}=\frac{(\gamma)_{i, j, k}}{\sum_{\text {all cells }}(\gamma)_{i, j, k}}=\frac{\left(\varepsilon_{s} V_{\text {cell }}\right)_{i, j, k}}{\sum_{\text {all cells }}\left(\varepsilon_{s} V_{\text {cell }}\right)_{i, j, k}}$
CFP $=1.0-\frac{\sum_{\text {all cells }}\left|\left(n_{t, n}\right)_{i, j, k}-(\gamma)_{n, i, j, k}\right|}{2.0}$

In these equations, $\left(n_{t, n}\right)_{i, j, k}$ and $(\gamma)_{n, i, j, k}$ are the normalized number of tracers and normalized solids content in cell $(i, j, k)$. The continuity fulfillment parameter (CFP) is defined such that it is always between zero and one. In an ideal situation when the normalized number of tracers and the normalized solids content are exactly equal to each other, the CFP equals one. In the worst possible case, the two aforementioned parameters have the largest possible difference with each other. As the summation of $n_{t, n}$ or $(\gamma)_{n, i, j, k}$ over all the computational cells is equal to one, the largest value of $\sum_{\text {all cells }}\left|\left(n_{t, n}\right)_{i, j, k}-(\gamma)_{n, i, j, k}\right|$ is equal to two. In this scenario, the CFP will be equal to zero. This parameter has been calculated for each of the simulations. The CFP evolution using different numbers of tracers is presented in Fig. 6. Besides that, some snapshots of the tracer positions in a slice through the centre from these simulation results are already presented in Fig. 4. As these figures show, the tracers' motion satisfies the continuity equation very well even when the number of tracers is only $5 \%$ of the number of particles in the bed.

It should be noted that in this method, the CFP can never be exactly equal to 1 , because each cell can only contain an integer number of tracers, whereas the local solids fraction can have arbitrary values.

\subsection{Average solids mixing}

As the solids mixing rate depends quite strongly on the instantaneously varying solids circulation patterns, the overall solids

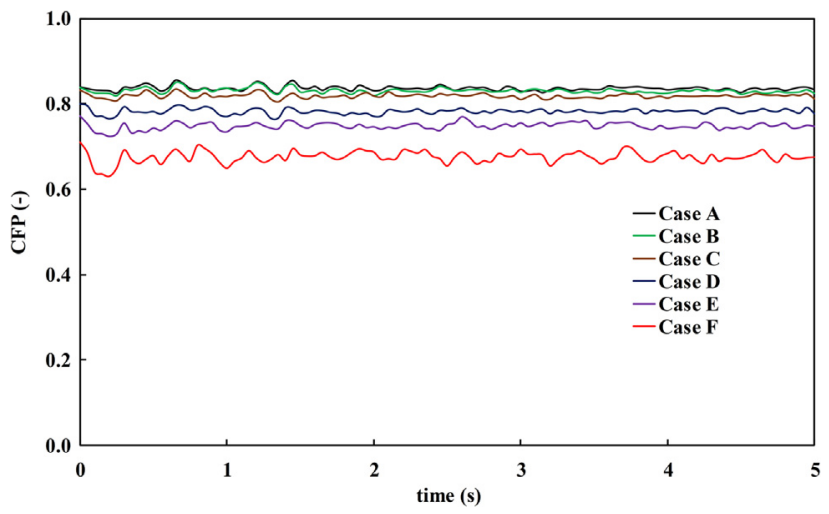

Fig. 6. Sensitivity of CFP to the number of tracers. 
mixing behavior was characterized by ensemble averaging several realizations of the MI. To this end, the evolution of the mixing index at various moments were computed, which were subsequently averaged. Subsequently, the average solids mixing index was fitted with a spline, which makes further analysis more straightforward. The simulation conditions for this section are presented in Table 5 . In these simulations, $u_{g}=0.7 \mathrm{~m} / \mathrm{s}$ was used. Fig. 7a shows an example of averaging over the instantaneous mixing index evolution. In this figure, the mixing index was obtained every $1.5 \mathrm{~s}$, while the first two seconds of the simulation were not considered to avoid start-up effects influencing the results [16]. Fig. 7b shows the sensitivity of the averaged solids mixing index to the number of realizations used. Based on Fig. 7, it can be concluded that the mixing index evolution was not very sensitive to the number of realizations. Nonetheless, we averaged all simulation results over more than four time-periods in the next sections to avoid any inaccuracy in the representation of the results.

\subsection{Time step and grid sensitivity analysis}

In this section, the sensitivity of the introduced technique to the time step and computational cell size is investigated. For this purpose, several simulations with different simulations settings were carried out (summarized in Tables 5 and 6). For each of the simulations, the mixing rate of particles based on the initial neighbor distance method was calculated. The sensitivity of the mixing index evolution to the time step and the radial, azimuthal and axial cell size are presented in Figs. 8, 9a-c respectively. In these simulations, superficial gas velocities of $0.7 \mathrm{~m} / \mathrm{s}$ and $0.8 \mathrm{~m} / \mathrm{s}$ were used for the grid size and time step sensitivity analysis respectively.

As shown in Fig. 8, the simulation results were not sensitive to the selected time step even when we used a relatively large time step of $8 \cdot 10^{-5} \mathrm{~s}$. The grid sensitivity analysis showed that the mixing index evolution is more sensitive to the axial cell size than the radial and azimuthal cell sizes. Fig. 9 shows that the mixing index is grid independent when the cell size is smaller than $5 d_{p}$ and $3 d_{p}$ in the radial and axial directions respectively. It also shows that the mixing results are not dependent on the number of cells in the azimuthal direction, provided that the number of cells in that direction is equal to or larger than 32 . The results were also quite similar even for the case using only 16 cells in the azimuthal direction. It should be noted that the dependency of the mixing index on the number of cells in the azimuthal direction may change if the bed diameter changes. We expect a stronger dependency for beds with larger diameters.
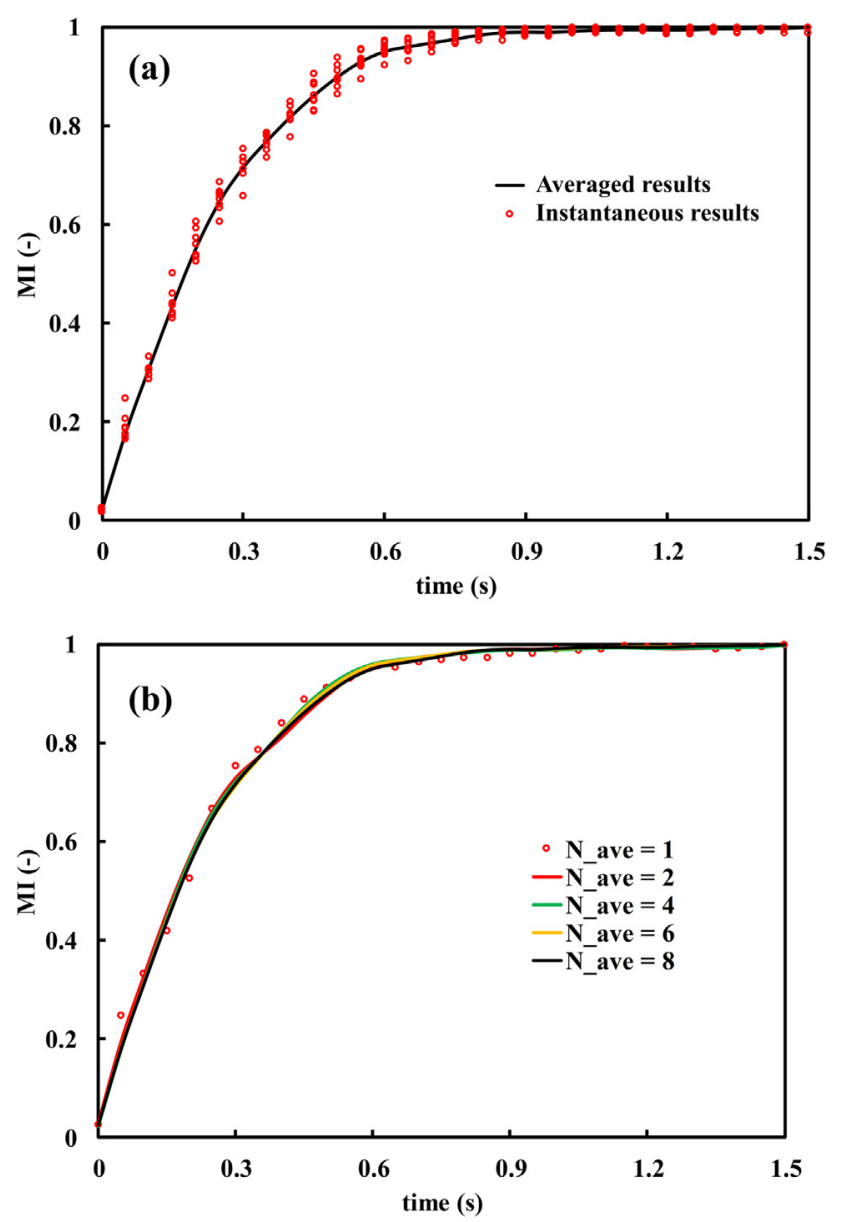

Fig. 7. Sensitivity of the ensemble averaged solids mixing index to the number of realizations used in the calculation.

\subsection{Strengths and drawbacks}

The method to represent tracer particles presented in this work has a couple of advantages over our previously introduced method for the calculation of the solids mixing [6]. It is based on a very simple and robust concept that makes it fairly accurate, while it can be implemented much more easily compared to the previous method. In contrast to the previous method, we are able to track individual tracers that leads to additional advantages. For example,

Table 5

Simulations' conditions for time step and grid size sensitivity analysis.

\begin{tabular}{|c|c|c|c|c|c|}
\hline Parameter & Value & Unit & Parameter & Value & Unit \\
\hline$D_{\text {bed }}$ & 0.06 & $\mathrm{~m}$ & $d_{p}$ & 0.9875 & $\mathrm{~mm}$ \\
\hline$H_{\text {bed }}$ & 0.18 & $\mathrm{~m}$ & $A R$ & 1.0 & - \\
\hline$\mu_{g}$ & $1.0 \cdot 10^{-5}$ & Pa s & $M W_{g}$ & 42.08 & $\mathrm{~g} / \mathrm{mol}$ \\
\hline$\Delta t$ & $2 \cdot 10^{-5}$ & $\mathrm{~s}$ & $\rho_{p}$ & 667.0 & $\mathrm{~kg} / \mathrm{m}^{3}$ \\
\hline$\Delta r$ & 0.003 & $\mathrm{~m}$ & $\mathrm{nr}$ & 10 & - \\
\hline$\Delta \theta$ & 0.19635 & - & $\mathrm{n} \theta$ & 32 & - \\
\hline$\Delta z$ & 0.003 & $\mathrm{~m}$ & $\mathrm{nz}$ & 60 & - \\
\hline$e_{w}, e$ & 0.97 & - & Discretizati & {$[14]$} & \\
\hline \multirow{2}{*}{\multicolumn{3}{|c|}{$\begin{array}{l}\text { Gas density: Ideal gas law } \\
\text { Number of tracers: } 20,000 \text { ( } \sim 10 \% \text { of number of particles) }\end{array}$}} & Drag relatic & . [15] & \\
\hline & & \multicolumn{4}{|c|}{ Number of tracers: 20,000 ( $\sim 10 \%$ of number of particles $)$} \\
\hline \multicolumn{6}{|c|}{ Frictional viscosity model: [9] } \\
\hline \multicolumn{6}{|c|}{ Boundary conditions: } \\
\hline \multicolumn{6}{|c|}{ Wall of the cylinder: no slip for gas and partial slip for particles } \\
\hline \multicolumn{6}{|c|}{ Axis of the cylinder: free slip for both phases } \\
\hline \multicolumn{6}{|c|}{ Outlet: prescribed atmospheric pressure } \\
\hline Inlet: pr & & & & & \\
\hline
\end{tabular}


Table 6

Settings used to test the grid size dependency of the method.

\begin{tabular}{lllll}
\hline Case & $\Delta \mathrm{r} / d_{p}$ & $\mathrm{n} \theta$ & $\Delta \mathrm{z} / d_{p}$ & $\Delta \mathrm{t}(\mathrm{s})$ \\
\hline AG & 2.53 & 32 & 3.04 & $2 \cdot 10^{-5}$ \\
BG & 3.04 & 32 & 3.04 & $2 \cdot 10^{-5}$ \\
CG & 3.80 & 32 & 3.04 & $2 \cdot 10^{-5}$ \\
DG & 5.06 & 32 & 3.04 & $2 \cdot 10^{-5}$ \\
EG & 3.04 & 32 & 2.53 & $2 \cdot 10^{-5}$ \\
FG & 3.04 & 32 & 4.05 & $2 \cdot 10^{-5}$ \\
GG & 3.04 & 32 & 5.06 & $2 \cdot 10^{-5}$ \\
HG & 3.04 & 40 & 3.04 & $2 \cdot 10^{-5}$ \\
IG & 3.04 & 16 & 3.04 & $2 \cdot 10^{-5}$ \\
\hline
\end{tabular}

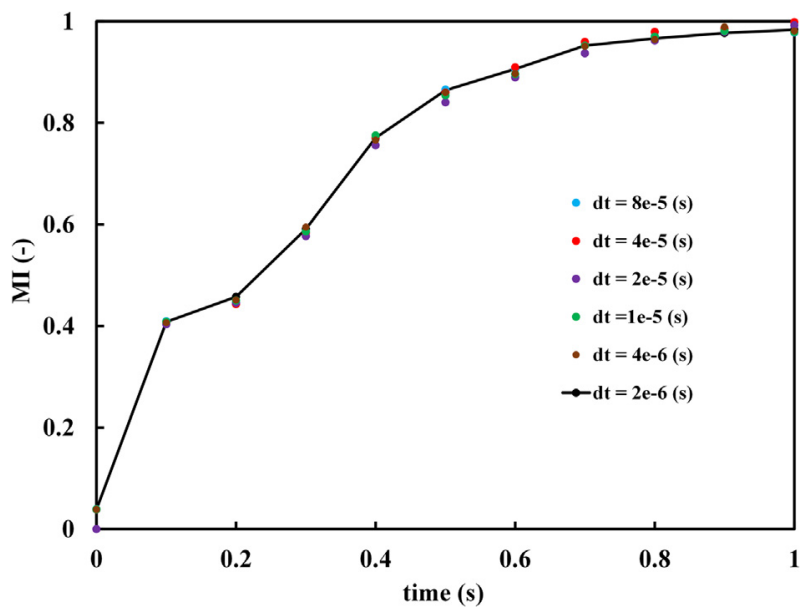

Fig. 8. Time step sensitivity analysis.

it is possible to use more accurate mixing indices like the initial neighbor distance method for the calculation of solids mixing. In addition, there is no necessity to perform two separate simulations for the calculation of the solids mixing in the vertical and horizontal directions.

The new method has also some drawbacks compared to the previous procedure. In the new method, the tracers can only be in one cell. Therefore, the CFP can never be equal to 1 , whereas in the previous method the CFP is always equal to 1 . Both techniques suffer from false diffusion. The false diffusion in the new technique exists even though we do not need to discretize any convection term like in the previous technique. This false diffusion can be shown by a simple example. Imagine that there is a plug flow of particles moving through a bed with a constant solids flux like illustrated in Fig. 10. In reality, we expect to reach two states as shown in Fig. 10a and b after two time-steps. However, based on our new method we may obtain results as for example shown in Fig. 10c and d. This false diffusion is due to the fact that we do not have any information from the solids motion on the particles' scale and it is only possible to obtain the solids movement pattern on the scale of one computational cell. This false diffusion can be reduced by considering the fact that particles which are close to a specific cell face are more probable to leave from that cell face than the particles that are located far from that cell face. For example, we can assume a specific form of decrease (e.g. linear, polynomial or exponential) in the leaving probability with the distance from a cell face. It should be noted that the proposed function must be normalized in a way that it does not cause deterioration in the fulfillment of continuity equation.

In addition, it should be remembered that the tracers are positioned in a random way in their new cell. It might be possible to reduce the effect of this part by considering the fact that tracers
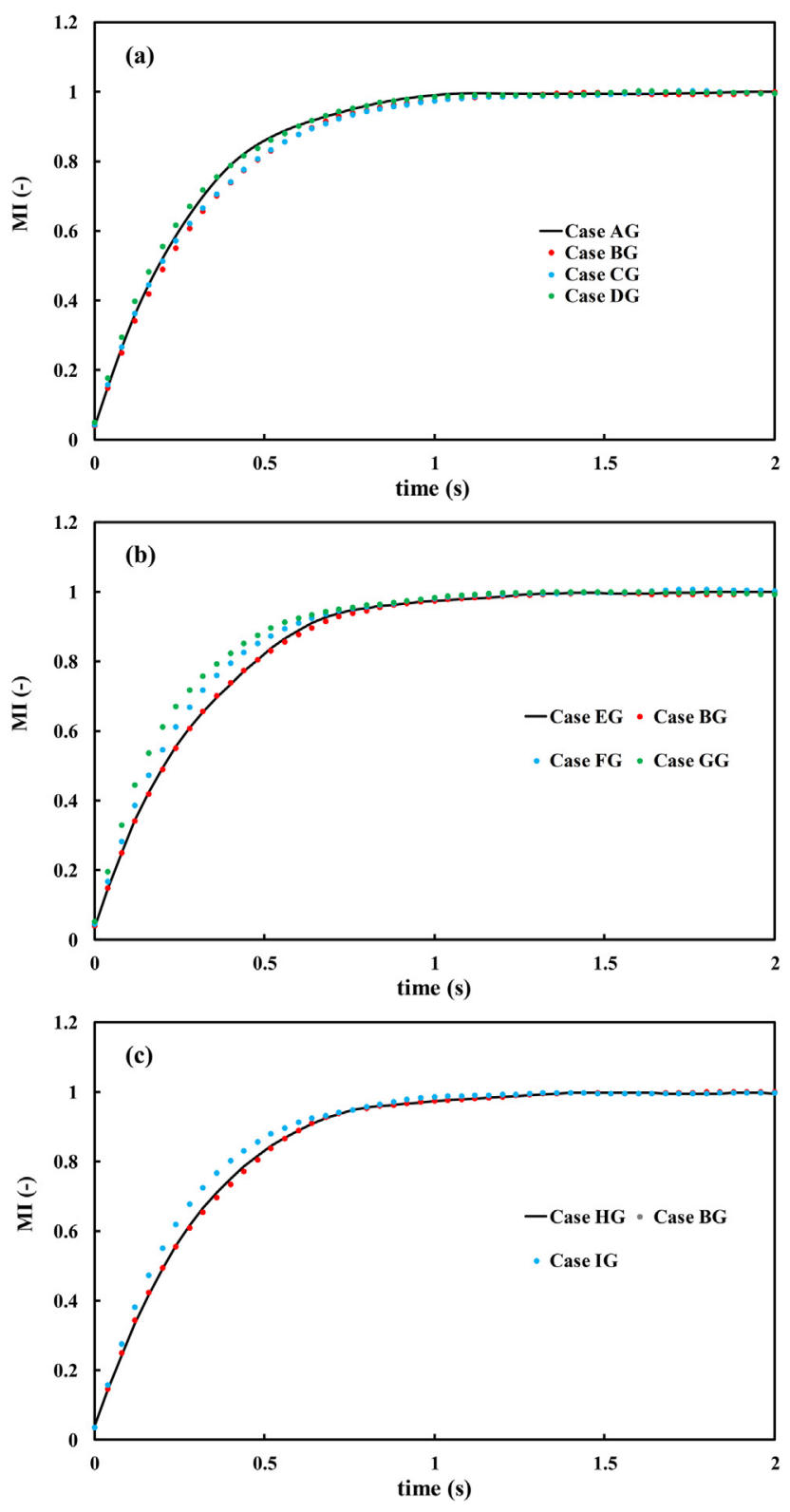

Fig. 9. Sensitivity of the mixing evolution to (a): the radial cell size, (b): the azimuthal cell size and (c): the axial cell size.

should not move more than $v_{\text {tracer }} \cdot \Delta \mathrm{t}$ within one time step. In this way, the false diffusion can be reduced to some extent, but the difficulty is related to determining the tracers' velocity. The tracers' velocity can be calculated based on the extent of their movement within one time step, but this method is not very accurate, as we do not know the tracers position accurately. We can also assume that the tracers should not move more than $v_{s, \text { cell }} \cdot \Delta \mathrm{t}$. Like the previous idea, this assumption must not cause deterioration in satisfying the continuity equation.

Moreover, the instantaneous tracers' outflux are not exactly proportional to the instantaneous TFM solids outflux, since we move the tracers based on probabilities and each tracer can only be in one cell at a time. We can also improve this part of the methodology by setting a restriction for the ratio between the solids flow rate and the tracers flow rate for all the cell faces. In this way, CFP values will be closer to 1.0 as well. It is also possible to divide the part of the algorithm which is related to the determination of the new positions of the tracers into two sections. For exam- 


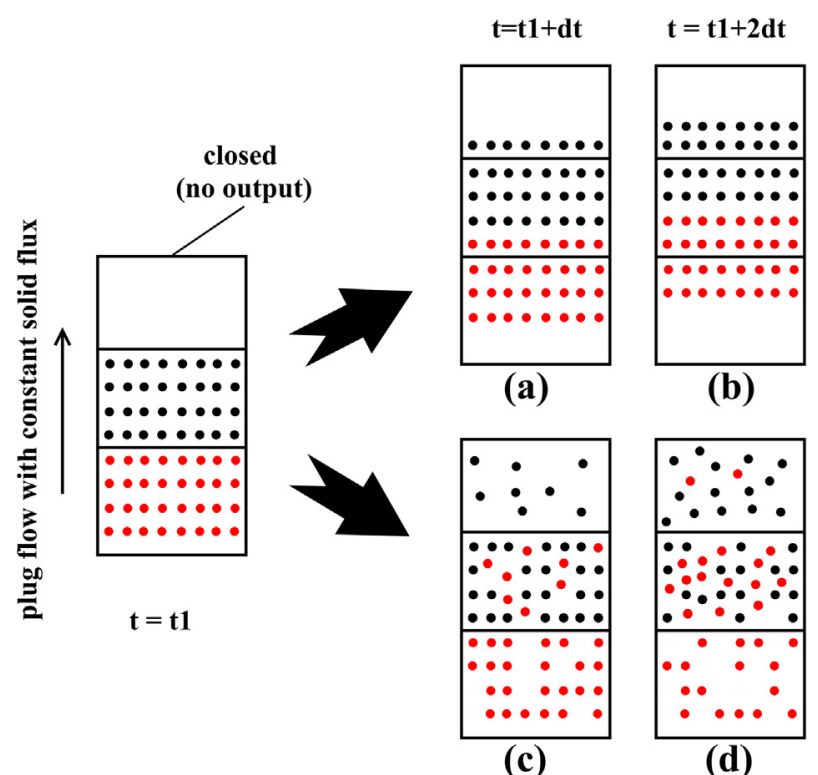

Fig. 10. An example of false diffusion in tracking of individual particles using the TFM.

ple, we first determine the leaving/staying probability distribution for the tracers in one cell at every time step. After the generation of random values between 0 and 1 for half of the tracers in that cell, we can decide how many of them will leave within the next time step and in which direction they will leave. Now, we can check how much the movement of tracers was in accordance with the fulfillment of the solids phase continuity equation. Then, we can redefine the leaving/staying probability distribution for that cell in accordance to the satisfaction of the continuity equation. Subsequentely, we can generate random values for the other half of the tracers, which we did not yet decide about whether they stay in the cell or whether they leave the cell; and if they leave in what direction. In this way, the CFP values will be much closer to one and some part of the false diffusion will be reduced. We can also break this part of the algorithm into more than two sections. For example, we can move only $10 \%$ of the tracers based on their leaving/ staying probability distribution and redefine this distribution and move the next $10 \%$ of tracers. Then, we recalculate the leaving/ staying distribution again and repeat this procedure till we decide about all the tracers. In this way, the average CFP will be closer to one.

Besides all the aforementioned issues, it should be noted that the presented method and the earlier presented approach are only applicable for monodisperse particles. If there are more than one particle types or if the particle properties change over time, then it is necessary to use multi-fluid models or population balances approaches respectively. There have been already several works for such systems and interested readers are referred to the works by van Sint Annaland et al. [17,18], Marchisio et al. [19] and Fan et al. [20].

\section{Results and discussion}

In this section, the simulation results investigating the effects of the superficial gas velocity and the restitution coefficient on the solids mixing rate are presented and discussed. These two parameters are influential parameters on the behavior of gas-solid fluidized beds. The simulation conditions are very similar to the simulation conditions in one of our earlier works related to poly- merization fluidized beds [1]. As was stated in that work, the solids mixing plays a very important role on the hot-spot formation and the results of this work are complementary to our earlier research.

\subsection{Effect of superficial gas velocity on solids mixing rate}

To study the effect of the superficial gas velocity on the solids mixing rate, various simulations at different gas velocities were performed. The simulation conditions were similar to the conditions presented in Table 5 with a few changes: In the current simulations, the bed is $0.24 \mathrm{~m}$ tall and we used 80 cells with a size of $0.003 \mathrm{~m}$ in the axial direction. The superficial gas velocity was varied from 0.4 to $1.1 \mathrm{~m} / \mathrm{s}$ and the time step was set to $2 \cdot 10^{-5} \mathrm{~s}$. The rest of the simulations' conditions are the same as reported in Table 5. The final results of these simulations are presented in Fig. 11. Fig. 11a shows the solids mixing evolution for various superficial gas velocities and Fig. 11b shows the solids mixing time. In this figure, $\mathrm{t}_{50 \%}, \mathrm{t}_{75 \%}, \mathrm{t}_{85 \%}$ and $\mathrm{t}_{90 \%}$ show the mixing time that is required to reach to $50 \%, 75 \%, 85 \%$ and $90 \%$ of the solids mixing index respectively.

As mentioned in our earlier research [1], the bubble formation rate increases with the superficial gas velocity, leading to faster solids circulation rates and solids mixing in the whole bed. Fig. 11 shows this effect in a quantitative way. Based on the results in Fig. 11, we can now quantify the changes in solids mixing with the superficial gas velocity. The current results also show that the solids mixing becomes less sensitive to the superficial gas velocity beyond $0.7 \mathrm{~m} / \mathrm{s}$, as the solid particles need to travel longer distances to be mixed with each other. These observations are in complete agreement with our earlier findings on the solids temperature distribution and its relation with the superficial gas velocity and solids mixing [1].
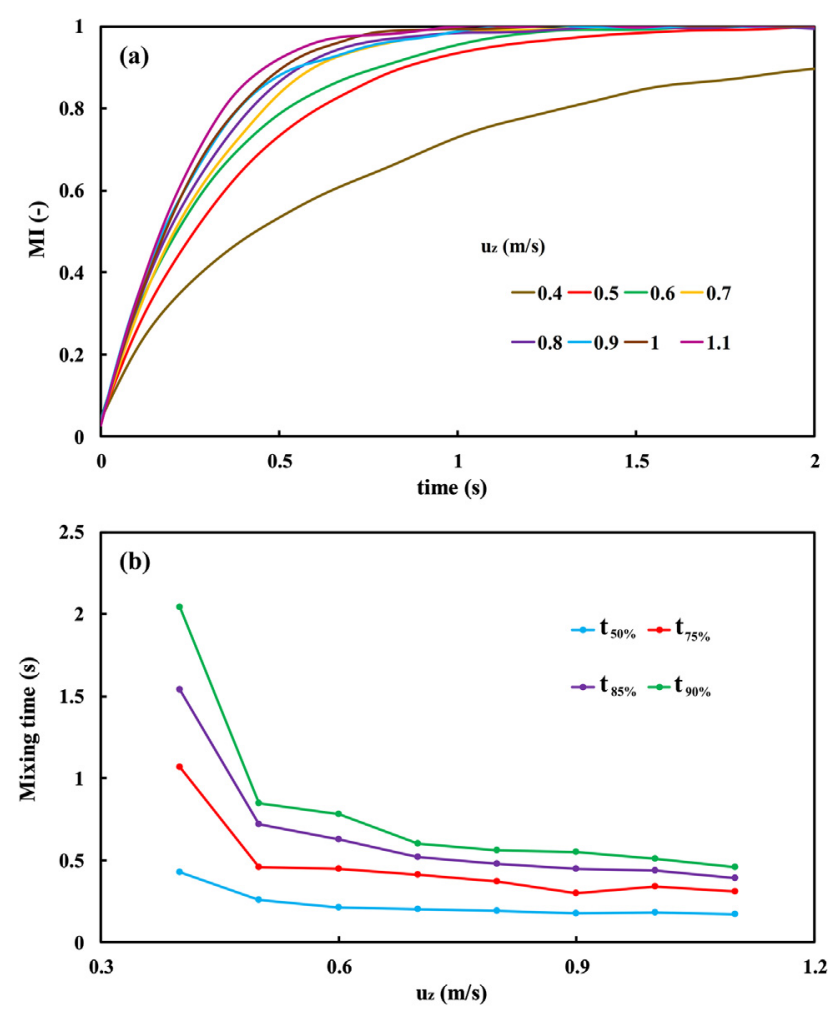

Fig. 11. Effect of superficial gas velocity on the solids mixing rate; (a): the timeaveraged mixing index evolution at various superficial gas velocities, (b): the mixing time at different superficial gas velocities. 


\subsection{Effect of restitution coefficient on solids mixing rate}

Restitution coefficients can change based on the physical properties of the particles, which in turn may depend on the operating conditions. For example, during the polymerization in gas solid fluidized beds, the particles' temperature may become close to their softening temperature. As a result, their restitution coefficient and the mixing pattern of particles may change. In this section, the effect of the restitution coefficient on the mixing rate of particles is presented and discussed. The simulation conditions for these cases are similar to the conditions presented in Table 5 with a superficial gas velocity of $0.8 \mathrm{~m} / \mathrm{s}$. In these simulations, the particle-particle restitution coefficient was varied from 0.6 to 0.99 . Fig. 12 shows the final results of these simulations. In Fig. 12a, the time-averaged mixing index evolution for simulations with different restitution coefficients is presented and Fig. 12b shows the solids mixing time for the performed simulations.

It can be observed that the effect of the restitution coefficient on the solids mixing rate is not as pronounced as the effect of the superficial gas velocity. The results also showed that the solids mixing rate decreases with for cases with higher restitution coefficients. This effect is much more significant for the cases with restitution coefficients larger than 0.8 in the performed simulations. The obtained results are in complete agreement with the findings of other studies [4,21]. As the bubble formation decreases for cases with more ideal restitution coefficients, the solids have a lower rate of circulation and consequently a lower mixing rate. So, if the restitution coefficient of poly-olefin particles decreases in the range of 0.99-0.6 with temperature as the particles becoming softer, we can expect a better solids mixing at high bed temperatures and hence a more isothermal behavior. We note that this
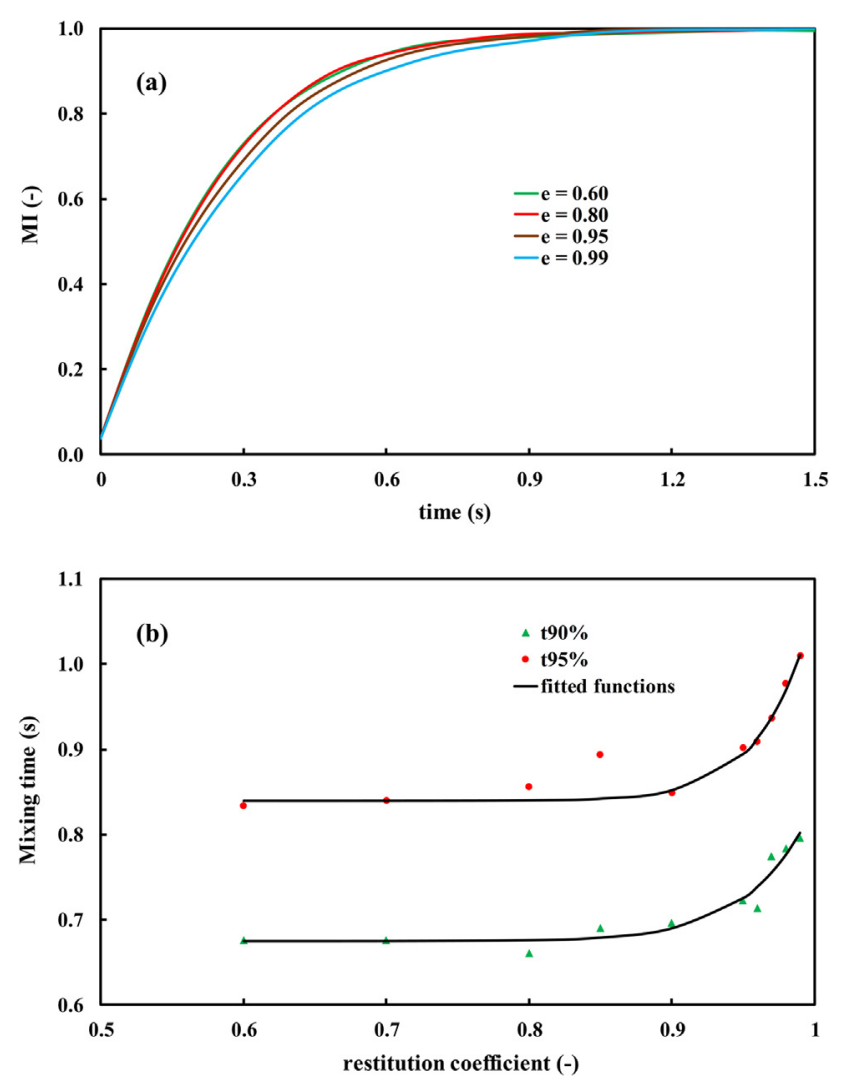

Fig. 12. Effect of restitution coefficient on the solids mixing rate; (a): mixing index evolution at different restitution coefficients; (b): solids mixing time for simulations with different restitution coefficients. analysis is done assuming that the polyolefin restitution coefficient decreases with temperature. Moreover, we did not consider the stickiness of polyolefin particles at temperatures close to their softening temperature. As we do not know the exact dependency of the restitution coefficient on the particle physical properties and the collision parameters, further studies are required in this area to shed light on these complex systems.

\section{Conclusions}

After successful implementation and verification of a new method to track tracer particles in the TFM, its benefits and drawbacks was studied. This new technique is very straightforward and can be implemented very easily. Moreover, it enables the use of the initial neighbor distance mixing index in the processing of the TFM results. This mixing index has several advantages over other mixing indices and its results are more accurate and reliable than the other methods. Additionally, the new approach opens a new window for combining the TFM with Lagrangian approaches. This technique has also some drawbacks. This method suffers from false diffusion, which can however be diminished by decreasing the computational cell size. For this reason, the sensitivity of the method to the grid size was investigated and the best settings were identified and several suggestions for further improvement of this algorithm were proposed. Subsequently, several simulations to study the effect of superficial gas velocity and restitution coefficient on the solids mixing rate were performed, where the main focus of these simulations was on quantifying the solids mixing rates in gas fluidized beds used for polyolefin production.

We found that the solids mixing rate increases with superficial gas velocity. This dependency is more pronounced when the gas velocity is low. In this study, the effect of restitution coefficient on the solids mixing rate was explored as well. It was found that the solids mixing rate decreases with increasing restitution coefficient. However, the dependency of the solids mixing rate to the superficial gas velocity was much more pronounced than its dependency to the restitution coefficient. In the performed simulations, the solids mixing rate did not change so much for restitution coefficients below 0.8 . On the other hand, a 19-20\% increase in $t_{90 \%}$ and $t_{95 \%}$ when increasing the restitution coefficient from 0.8 to 0.99 was observed. The changes in the solids mixing rate with the superficial gas velocity and the restitution coefficient was caused mainly by their effect on the bubble formation rate, bubble interactions and bubble size. Further studies on these aspects of fluidized bed behavior and the functionality of restitution coefficients to the physical properties of the particles are required to further improve the predictions.

\section{Acknowledgement}

This work is part of the Research Programme of Dutch Polymer Institute (DPI) as a project number \# 751.

\section{References}

[1] M. Banaei, J. Jegers, M. van Sint Annaland, J.A.M. Kuipers, N.G. Deen, Solid temperature distribution in gas fluidized beds with heat production, Ind. Eng. Chem. Res. 56 (2017) 8729-8737, https://doi.org/10.1021/acs.iecr.7b00338.

[2] J. Ding, D. Gidaspow, A bubbling fluidization model using kinetic theory of granular flow, AIChE J. 36 (1990) 523-538, https://doi.org/10.1002/ aic.690360404.

[3] M.J.V. Goldschmidt, R. Beetstra, J.A.M. Kuipers, Hydrodynamic modelling of dense gas-fluidised beds: comparison and validation of 3D discrete particle and continuum models, Powder Technol. 142 (2004) 23-47, https://doi.org/ 10.1016/j.powtec.2004.02.020.

[4] M.J.V. Goldschmidt, J.A.M. Kuipers, W.P.M. Van Swaaij, Hydrodynamic modelling of dense gas-fluidised beds using the kinetic theory of granular flow: effect of coefficient of restitution on bed dynamics, Chem. Eng. Sci. 56 (2001) 571-578, https://doi.org/10.1016/S0009-2509(00)00262-1. 
[5] L. Huilin, H. Yurong, D. Gidaspow, Y. Lidan, Q. Yukun, Size segregation of binary mixture of solids in bubbling fluidized beds, Powder Technol. 134 (2003) 8697, https://doi.org/10.1016/S0032-5910(03)00126-8.

[6] M. Banaei, N.G. Deen, M. van Sint Annaland, J.A.M. Kuipers, Particle mixing rates using the two fluid model, Particuology J. (2018), https://doi.org/10.1016/ j.partic.2017.01.009, in press.

[7] J.J. Nieuwland, M. van Sint Annaland, J.A.M. Kuipers, W.P.M. van Swaaij, Hydrodynamic modeling of gas/particle flows in riser reactors, AIChE J. 42 (1996) 1569-1582, https://doi.org/10.1002/aic.690420608.

[8] D. Ma, G. Ahmadi, An equation of state for dense rigid sphere gases, J. Chem. Phys. 84 (1986) 3449-3450, https://doi.org/10.1063/1.1706155.

[9] A. Srivastava, S. Sundaresan, Analysis of a frictional-kinetic model for gasparticle flow, Powder Technol. 129 (2003) 72-85, https://doi.org/10.1016/ S0032-5910(02)00132-8.

[10] P.C. Johnson, R. Jackson, Frictional-collisional constitutive relations for granular materials, with application to plane shearing, J. Fluid Mech. 176 (1987) 67-93.

[11] R. Ocone, S. Sundaresan, R. Jackson, Gas-particle flow in a duct of arbitrary inclination with particle-particle interactions, AIChE J. 39 (1993) 1261-1271, https://doi.org/10.1002/aic.690390802.

[12] V. Verma, N.G. Deen, J.T. Padding, J.A.M. Kuipers, Two-fluid modeling of threedimensional cylindrical gas-solid fluidized beds using the kinetic theory of granular flow, Chem. Eng. Sci. 102 (2013) 227-245, https://doi.org/10.1016/j. ces.2013.08.002.

[13] N.G. Deen, W. Godlieb, G. Sander, J.A.M. Kuipers, Numerical analysis of solids mixing in pressurized fluidized beds, Ind. Eng. Chem. Res. 49 (2010) 52465253, https://doi.org/10.1021/ie9014843.
[14] P. Roe, Characteristic-based schemes for the Euler equations, Annu. Rev. Fluid Mech. 18 (1986) 337-365, https://doi.org/10.1146/annurev.fluid.18.1.337.

[15] M.A. van der Hoef, R. Beetstra, J.A.M. Kuipers, Lattice-Boltzmann simulations of low-Reynolds-number flow past mono- and bidisperse arrays of spheres: results for the permeability and drag force, J. Fluid Mech. 528 (2005) 233-254, https://doi.org/10.1017/S0022112004003295.

[16] M.J. Rhodes, X.S. Wang, M. Nguyen, P. Stewart, K. Liffman, Study of mixing in gas-fluidized beds using a DEM model, Chem. Eng. Sci. 56 (2001) 2859-2866, https://doi.org/10.1016/S0009-2509(00)00524-8.

[17] M. van Sint Annaland, G.A. Bokkers, M.J.V. Goldschmidt, O.O. Olaofe, J.A.M. Kuipers, Development of a multi-fluid model for poly-disperse dense gas-solid fluidised beds, part I: model derivation and numerical implementation, Chem. Eng. Sci. 64 (2009) 4222-4236, https://doi.org/10.1016/j.ces.2009.06.044.

[18] M. van Sint Annaland, G.A. Bokkers, M.J.V. Goldschmidt, O.O. Olaofe, J.A.M. Kuipers, Development of a multi-fluid model for poly-disperse dense gas-solid fluidised beds, part II: segregation in binary particle mixtures, Chem. Eng. Sci. 64 (2009) 4237-4246, https://doi.org/10.1016/j.ces.2009.06.043.

[19] D.L. Marchisio, J.T. Pikturna, R.O. Fox, R.D. Vigil, A.A. Barresi, Quadrature method of moments for population-balance equations, AIChE J. 49 (2003) 1266-1276, https://doi.org/10.1002/aic.690490517.

[20] R. Fan, D.L. Marchisio, R.O. Fox, Application of the direct quadrature method of moments to polydisperse gas-solid fluidized beds, Powder Technol. 139 (2004) 7-20, https://doi.org/10.1016/j.powtec.2003.10.005.

[21] B.P.B. Hoomans, J.A.M. Kuipers, W.J. Briels, W.P.M. van Swaaij, Discrete particle simulation of bubble and slug formation in a two-dimensional gas-fluidised bed: a hard-sphere approach, Chem. Eng. Sci. 51 (1996) 99-118, https://doi. org/10.1016/0009-2509(95)00271-5. 